\title{
The development of subjective group dynamics: When in-group bias gets specific
}

\author{
Dominic Abrams'*, Adam Rutland', Lindsey Cameron' and \\ José M. Marques ${ }^{2}$ \\ ' University of Kent, UK \\ ${ }^{2}$ University of Porto, Portugal
}

\begin{abstract}
Children aged 6-7 years and 10-11 years evaluated an in-group or out-group summer school and judged in-group or out-group members whose attitudes towards the summer schools were either normative or anti-normative. According to a subjective group dynamics model of intergroup processes, intergroup differentiation and intragroup differentiation co-occur to bolster the validity of in-group norms. The hypothesis that this process develops later than simple in-group bias was confirmed. All children expressed global in-group bias, but differential reactions to in-group and outgroup deviants were stronger among older children. Moreover, the increasing relationship, with age, between in-group bias and evaluative preferences for in-group and out-group members that provide relative support to in-group norms, is mediated by the degree of perceptual differentiation among group members.
\end{abstract}

The present article examines developmental changes in judgments of deviant and normative group members within in-groups or out-groups. Social exclusion is a serious social problem. Being rejected by one's peers can cause increases in antisocial behaviour, aggression, lowered intellectual performance, self-defeating behaviour and a series of other maladaptive responses (Twenge \& Baumeister, in press; Williams, 2001). Children who are cast as misfits may be bullied, victimized or disadvantaged in other ways (Crick, 1997; Hoover, Oliver, \& Hazler, 1992; Schuster, 1996). Therefore, an important social task that children face is to work out when their own and others' behaviour contravenes social norms, and to decide how to respond when such norms are contravened (Emler \& Reicher, 1995). Investigation of responses to social conformity and deviance may provide useful insight into ways of ameliorating potentially damaging consequences of social inclusion and exclusion processes among

*Requests for reprints should be addressed to Dominic Abrams, Department of Psychology, Keynes College, University of Kent at Canterbury, Canterbury CT2 7NP, UK (e-mail: D.Abrams@kent.ac.uk). 
children. However, it is important to note that children may reject or accept one another on the basis of different criteria. In particular, they may focus on social category memberships (e.g. in-group versus out-group), or on individual behaviour.

The majority of research into children's intergroup attitudes has used measures of group preference (see reviews by Aboud, 1988; Aboud \& Amato, 2001; Katz, 1976; Nesdale, 2001), in which children are required to make a forced choice between targets that represent whole social groups (e.g. a boy vs. a girl). This methodology excludes the possibility of evaluating how children use available information to judge individual ingroup and out-group members and how these evaluations relate to their overall intergroup attitudes. In contrast, research on group deviance in adults has traditionally focused on evaluations of group members. Typically, this research has examined behaviour or characteristics that reduce the group's distinctiveness, contradict its stereotype, or threaten its goals (Levine, 1989). According to self-categorization theory, in-group norms embody the behaviours or features that members should adopt, and that maintain distinctiveness from the out-group (Turner, Hogg, Oakes, Reicher, \& Wetherell, 1987). Previous research with adults has examined how deviant members of in-groups and out-groups are evaluated (e.g. Abrams, Marques, Bown, \& Henson, 2000; Marques, Abrams, Paez, \& Martinez-Taboada, 1998, Marques, Abrams \& Serôdio, 2001). However, relatively little is known about the development of judgments of specific normative and deviant members of social groups. Children undoubtedly experience members of their groups whose behaviour violates in-group norms (e.g. team members who prefer the other team, children who won't join in a game, children who prefer opposite-gender typical activities). The present article reports a developmental study that examines how children evaluate deviants in an intergroup context.

\section{Development of in-group preference}

In-group preferences are known to emerge relatively early in childhood. For example, research on ethnicity and gender has shown that by the age of 3 or 4 years children normally express more positive attitudes towards their own group than towards others (see Aboud, 1988; Bigler, 1995; Bigler \& Liben, 1992; Nesdale, 2001; Powlishta, 1995a, 1995b; Powlishta, Serbin, Doyle, \& White, 1994; Yee \& Brown, 1994). Studies have even shown in-group favouritism in minimal or transitory groups at around 5 years of age (e.g. Bigler, 1995; Bigler, Brown, \& Markell, 2001; Bigler, Jones, \& Lobliner, 1997; Nesdale \& Flesser, 2001; Spielman, 2000; Vaughan, Tajfel, \& Williams, 1981).

Cognitive-developmental theory is probably the most well-known account of how intergroup attitudes develop in childhood (see Aboud, 1988; Aboud \& Amato, 2001; Doyle \& Aboud, 1995; Katz, 1976; Lambert \& Klineberg, 1967; Powlishta et al., 1994). This theory contends that only with cognitive development do children stop defaulting to the use of social categorization and consequently show a reduction in intergroup discrimination. When children move away from the 'sociocentric' (Piaget \& Weil, 1951) stage of development their perceptions cease to focus only on group differences, and they become capable of making social judgments also on the basis of unique interpersonal characteristics of an individual. Therefore, cognitive-developmental theory predicts that, as children get older and increase in cognitive maturity, the availability of information about individuals' characteristics should dominate perception, and thereby help to reduce intergroup biases. Aboud's social-cognitive developmental theory (Aboud, 1988) proposes a sequence of development involving shifts in the child's focus of attention 'from self, to groups, and finally to individuals' 
(p. 23). As a result, at the third stage of the sequence, 'greater attention to individuals should be accompanied by even lower levels of prejudice ... . This is not to say that all people will be evaluated positively, but the criterion will not be [ethnic] group membership' (p. 25).

There is evidence that, with age, children often show less negative intergroup attitudes, especially in relation to ethnicity (see, for a review, Aboud, 1988; Aboud \& Amato, 2001). Despite this attenuation, there is evidence that older children can still show significant levels of intergroup bias (e.g. Abrams, 1985, 1989; Augoustinos \& Rosewarne, 2001; Bennett, Lyons, Sani, \& Barrett, 1998; Black-Gutman \& Hickson, 1996; Rutland, 1999; Verkuyten, Masson, \& Elffers, 1995; Yee \& Brown, 1994). Moreover, the idea that intergroup discrimination in general decreases with age seems strange in light of the apparent ease with which adolescents can be induced to show ingroup bias (see Abrams \& Brown, 1989; Brewer \& Brown, 1988; Hewstone, Rubin, \& Willis, 2002).

An interesting possibility that we consider in the present research is that as children get older they sustain their social identification with particular categories and groups through evaluations of individual group members, and rely less on global evaluations of the entire group. In other words, although they develop the ability to engage in multiple classifications and perceive within-group differences (Bigler, 1995; BlackGutman \& Hickson, 1996; Doyle \& Aboud, 1995; Katz, Sohn, \& Zalk, 1975, Martin, 1989), this allows them to reinforce their identification with social categories. The children do not abandon or reduce category-based judgments, but instead may sustain important category differences by approving of individuals (i.e. out-group deviant and in-group normative targets) who provide relative support for in-group categories. This prediction fits with evidence that suggests that between 7 and 9 years of age children show important social-cognitive transitions from judgments based on a few primarily physical and concrete categories (e.g. sex, hair colour) to ones formulated using a multitude of abstract social and psychological categories (e.g. intelligent, altruistic, friendly) (Cameron, Alvarez, Ruble, \& Filigni, 2001; Ruble \& Dweck, 1995). In addition, children develop the ability to engage in complex social comparisons between individuals and groups based on dispositional characteristics, such as shared attitudes and beliefs (Ruble \& Frey, 1991; Rutland, 1999; Sani, Bennett, Agostini, Malucchi, \& Ferguson, 2000).

\section{Adult responses to deviant group members}

Deviance from group norms is often accompanied by antisocial or undesirable behaviour, and this means that there is an added 'moral' dimension that may serve to justify negative treatment of these deviants. However, it is important to distinguish between general rule-breaking or unattractiveness and deviance that contravenes specific norms that are important for the maintenance of group differences. For example, in general, behaving fairly or positively toward others is judged favourably. Nevertheless, the same behaviour may have different implications if directed toward ingroup versus out-group members (Abrams, Marques, Bown, \& Dougill, 2002; Zdaniuk \& Levine, 2001). Group members may vary in the degree to which they follow norms prescribed by their own group. When group membership is salient or when people identify with the group, instances of deviance from these prescriptive norms may threaten the in-group consensus, and hence endanger positive social identification with the group. The present article investigates how children react to deviation that is anti- 
normative within in-groups or out-groups. Previously, we have defined anti-norm deviants as group members who reject their group's norms in a way that implies movement towards the normative attitudes or behaviour attributed to a contrasting group (Abrams et al., 2000).

Social identity theory (e.g. Tajfel, 1981; Tajfel \& Turner, 1986), holds that people are motivated to sustain a positive social identity. Our model of subjective group dynamics (SGD; Abrams et al., 2000; Marques, Paez, \& Abrams, 1998) proposes that the subjective value of the in-group is sustained when other individuals endorse prescriptive in-group norms, and is threatened when others endorse the norms of opposing groups (Marques, Paez, \& Abrams, 1998). Therefore, even though people may differentiate in-groups from out-groups as a whole (e.g. showing general favouritism to the in-group), they also differentiate among members within the groups in a way that favours those individuals who provide relative endorsement of the in-group over members who provide relative endorsement of the out-group. The normal pattern of ingroup favouritism is often eliminated, and sometimes reversed, when people judge antinormative group members. Evidence is consistent with the idea that it is the relative position of the group members within a group, rather than their particular behaviour, that affects judgments and evaluations (Marques, Abrams et al., 1998). In summary, a consequence of subjective group dynamics is that people tend to feel less favourable towards in-group members whose attitudes or behaviour suggest relative rejection of ingroup norms, and they feel more favourable towards out-group members whose behaviour provides relative support for in-group norms. Marques, Abrams et al. (1998, Experiments 1, 2, 3) demonstrated this effect among students in minimal groups when the deviants endorsed positions in line with the opposing group, and Abrams et al. (2000, Experiment 2; Abrams et al., 2002) found a similar effect for real group memberships among teenagers, university students and bank employees.

\section{Children's evaluations of individual group members}

A limited number of studies have asked children to evaluate or make judgments relating to individual members of social groups. For example, a recent study by Bigler et al. (2001) into the effect of group status on children's intergroup attitudes presented children with individuating information about peers. Despite that information, the children still showed significant levels of intergroup discrimination. This could have resulted from the use of novel social groups ('blue' and 'yellow') without distinct ingroup social norms.

Nesdale (1999) also presented children with individuating information about traits but utilized a social category used less readily with increasing age, namely the ethnic category (see Aboud, 1988). He examined how children's ethnic group preferences were affected by the knowledge that an in-group or out-group person did not fit with the group stereotype. Anglo-Australian children from three age groups (8, 10 and 12 years) listened to a story about both an in-group Anglo-Australian boy and an out-group Vietnamese boy, each of whom showed equal numbers of ethnic stereotype-consistent and -inconsistent traits. Older children produced better memory recall for in-group vs. out-group story character's stereotype-inconsistent vs. consistent traits. More importantly, children aged between 10 and 11 years expressed greater liking for the outgroup than the in-group character, whereas the younger children preferred the in-group member.

The results of Nesdale's (1999) study suggest that the use of individuating 
information about group members develops later than intergroup differentiation. However, that research did not address the question of the linkage between intergroup and intragroup judgments. Specifically, the subjective group dynamics model holds that the motivation to favour the in-group over the out-group, as a whole, functions in concert with the motivation to favour individual group members from either group who show relative support for the in-group. To assess the operation of subjective group dynamics (SGD) directly it is necessary to invoke an explicit in-group vs. out-group comparison. In addition, the SGD model is concerned with norms rather than traits or stereotypes, and there seems to be little research that has examined intergroup norm violation effects on children's judgments of group members. In addition, most studies of intergroup evaluations by children simply present a normative group member as the target of judgment. However, the SGD model concerns differentiation between normative and deviant targets within groups, and this is best explored by asking participants to judge both types of target (see Abrams et al., 2000). The present study therefore examines judgments of deviant members relative to normative members within in-groups or out-groups. Finally, for subjective group dynamics to function, it is necessary that group members be able to detect normative differences within groups. Previous research has suggested that children below the age of 10 years often lack detailed stereotype knowledge of the national in-group and out-groups (see Barrett \& Short, 1992; Rutland, 1999; Sani \& Bennett, 2001). This may mean that, when stereotype information is presented (e.g. Nesdale, 1999) younger children may lack the stereotype knowledge required to understand inconsistencies. In contrast, prescriptive behavioural norms tend to be quite unambiguous and unidimensional, and so it seems likely that even younger children may have a basic awareness of such norms. One goal of the present research is to examine whether younger children are aware of deviations from group norms, and how such awareness affects evaluations of individual group members.

The present research tests the hypothesis that subjective group dynamics develop later than simple in-group bias, and that evaluative differentiation among group members depends on distinguishing among them in terms of their adherence to group norms. Our research is set in the context of a summer school and we used the fact that two similar schools operate within a locality to make intergroup comparisons salient to the children. Much of the classic research in intergroup conflict and cooperation has been conducted in similar settings (e.g. Sherif, 1966; Sherif, Harvey, White, Hood, \& Sherif, 1961). This particular intergroup setting was also useful because the children had low familiarity with the other individuals in each group, and group membership was highly meaningful, but temporary, cross-cutting many other longstanding categories (e.g. the children's own school, gender and age). As a result we were able to manipulate the apparent normativeness and deviance of stimulus group members very precisely. Indeed, we ensured that, whereas in-group and out-group normative members simply said positive things about their respective groups, deviant group members expressed a positive attitude towards both groups. In fact, the deviants in the in-group condition and the out-group condition expressed identical attitudes. This manipulation ensured that there were no confounds between the overall positivity or social desirability of different group members and whether they were normative or deviant, or in-group or out-group members. The only variation was in terms of relative support for the in-group and out-group. In order to examine whether there are developmental changes in reactions to normative and deviant group members, we compared responses from 6-7-year-olds and 10-11-year-olds. This age range was chosen 
because evidence suggests that between these ages children develop the ability to engage in multiple classification (e.g. Bigler, 1995; Doyle \& Aboud, 1995), a necessary requirement for intragroup differentiation.

\section{Overview and hypotheses}

Two summer play-school schemes agreed to participate in this study. We used $2 \times 2$ design within each of two age groups, 6-7 and 10-11 years. Children received information about either members of the in-group scheme or the out-group scheme. Normative members made two positive statements about their summer school. Deviant members made one positive statement about their school and one positive statement about the other summer school. All children were asked to make judgments about both groups as a whole, and about a normative member and a deviant member of the target group.

\section{Subjective group dynamics hypotheses}

We expected children to show in-group bias when they made global judgments about the two groups. However, reactions to deviants should involve two processes. First, the extent of deviation at the intragroup level may be perceived. This is necessary, but not sufficient, to provoke negative evaluations and judgments of the deviants (Marques, Abrams et al., 1998, Experiment 3). More relevant is the meaning attached to such deviance. That is, perceivers must not only be aware of differences within groups, but must interpret those differences in terms of their implications for group norms. The particular evaluation of a deviant will be determined by the relative support they provide for in-group norms in comparison with normative members, as reflected by perceptions of the perceived acceptability or inclusion of the members in the group. Out-group members who deviate by acknowledging the value of the in-group should help validate prescriptive in-group norms. Because an underlying motive for evaluations of these members is to sustain in-group social identity, out-group deviants should be evaluated more positively than normative out-group members (who only acknowledge the value of the out-group). Conversely, in-group members who deviate by acknowledging the value of the out-group should threaten prescriptive in-group norms. Therefore, in-group deviants should be evaluated less positively than normative ingroup members (who only acknowledge the value of the in-group). Therefore, our general prediction is that, when subjective group dynamics are operating, participants will favour an in-group normative member over an in-group deviant, but will favour an out-group deviant member over an out-group normative member (as found among adults, see Abrams, Marques, Randsley de Moura, Hutchison, \& Bown, in press; Cameira, Marques, Abrams, \& Serôdio, 2001).

A further aspect of the subjective group dynamics approach is that intergroup differentiation and intragroup differentiation should co-occur (Abrams et al., 2000; Marques, Abrams et al., 1998). Thus, the more individuals show general bias in favour of their in-group, the more they should relatively favour in-group and out-group members who help to validate the in-group norm.

\section{Developmental differences}

Subjective group dynamics requires the application and interpretation of multiple abstract classifications and social comparisons (Bigler, 1995; Black-Gutman \& Hickson, 1996; Cameron et al., 2001; Doyle \& Aboud, 1995; Katz et al., 1975; Ruble \& Dweck, 
1995). Therefore, we expect subjective group dynamics to emerge later than simple ingroup preferences and than the ability simply to detect that individuals behave differently from one another. Among both age groups we expect children to express global intergroup bias, and to detect that normative and deviant individuals behave differently, with deviants being less typical of the wider group. However, it seems likely that older children will have a more sophisticated understanding of the implications of atypicality in an intergroup context. This should be revealed by older children's expectations of how acceptable the individuals will be to other members of each group, and their evaluations of those individuals.

Cognitive-developmental theory would expect that evaluations should increasingly be based on individuated processing with age. In the present study, all targets expressed only positive attitudes. Thus, the general likeableness of targets was assumed to be equal. As a result, one outcome could be that older children focus on the individual characteristics and do not favour in-group over out-group members. However, a second possibility is that older children might judge targets according to their adherence to moral rules, such as codes of fairness and equality (Damon, 1977; Hoffman, 2000). If this happens, more even-handed (deviant) individuals might be judged more favourably than partisan (normative) individuals, regardless of which group they belong to. However, both of these possible patterns of evaluation would cause a reduction in in-group bias when judging target individuals because targetbehaviour information would either attenuate, or cancel out, the effects of target category membership.

In contrast to cognitive-developmental theory, the subjective group dynamics hypothesis is that older children will be more likely to interpret differences among individuals with reference to their fit to group norms. Therefore, rather than evaluating all targets equally favourably, older children will differentiate more strongly between those whose behaviour is normative and deviant, in terms of their acceptability for inclusion in each group. They will then favour those targets whose behaviour is relatively in-group supportive. Therefore, with age, we expect that category membership will be used more systematically as the frame of reference for judging target behaviour.

\section{Method}

\section{Norm check}

We conducted a small preliminary study to ensure that that children could distinguish between the typicality of statements designed to be normative and deviant. Nine 7-yearolds and twelve 11-year-olds from a school in south-east England were asked to estimate the proportion of children in their school who would agree with a series of statements made by a child from their school.

Children were tested individually by a female experimenter. They were told that they would be presented with some questions about different schools. First the response format was explained. A picture of 12 stick people was presented and described as 'a group of children'. Then, it was explained how to answer the question, 'How many of these children do you think would say "I love eating sweets"?' A series of response scales was presented, showing proportionate numbers of stick people with labels representing all the children, most of the children, about half of the children, a few of 
the children and none of the children. This was later scored as a scale from 1 (none) to 5 (all). Once the child's responses indicated that he or she understood how to use the response format, the main questionnaire was presented. Children were reminded that answers were completely anonymous and that there were no right or wrong answers; we just wanted to know what they thought.

Children were then asked to 'Think about children from [name of their school]. Here is a group of 15 children from [School] talking about school. Think about what the children would say about [School]. Below are some things children might say about school. How many children in this group would say these statements?'. There followed a series of five 'normative' and one 'deviant' statements, used in the main study, with the response scale presented below each one. The normative statements were positive statements about the school, such as 'I really like [School]', and '[School] is a great place to be', and were used as attitude stimuli in the main study. The deviant statement referred to a comparable local out-group school, and stated '[out-group school] would be good because there are lots of exciting things to do there'. These statements were designed such that evaluations of the two schools were independent - praise for one school did not necessarily imply criticism of the other. However, we expected that praise for the out-group school would be regarded as deviant. We also presented two items that were more blatant - in which the evaluations of the schools were interdependent. The normative bias statement was 'No other school in [Town] is better than [in-group school]'. The deviant bias statement was 'No other school in [Town] is better than [out-group school]'. Although the design of the main study precluded use of these two items, they still provide a useful check on the normative expectations of judgments about in-group and out-group schools.

We averaged the responses to the five normative items and compared this score with the response to the deviant item. A mixed ANOVA, with age group as a betweenparticipants variable and item type (normative vs. deviant) as a within-participants variable revealed no significant effect of age but a significant effect of item type, $F(1,19)$ $=15.49, p<.001$. Normative attitudes were expected to be expressed by a larger number of children $(M=4.02, S D=0.47)$ than was the deviant attitude $(M=2.95, S D=$ 1.02). Next, we analysed responses on the two blatant items. Again, there was a significant effect only of item type, $F(1,19)=28.08, p<.001$. The normative statement was expected to be expressed by more children $(M=3.81, S D=0.93)$ than was the deviant statement $(M=2.14, S D=0.91)$.

These results confirm that both younger and older children expected schoolchildren to say positive things about their in-group school but not about an out-group school. Children appear to have clear expectations regarding the expression of in-group supporting and out-group supporting attitudes.

\section{Design and participants}

We used a 2 (Group: In-group vs. Out-group) $\times 2$ (Age: 6-7, 10-11) betweenparticipants $\times 2$ (Member: Normative vs. Deviant) within-participants design.

Sixty-seven children attending two summer schools in the same district of south-east England sampled in our preliminary study participated. (The schemes both provided sports and other activities for children from 10 a.m. to 4 p.m. each weekday.) Most children were white and from predominantly middle-class backgrounds. Data from three children were discarded because they showed problems in understanding or completing the measures (e.g. children who were new to the area and said they did not 
know about the other summer school). Data were collected from 41 boys and 23 girls from two age groups: $6-7$ years $(n=32, M=82.47$ months, $S D=7.63$ months); $10-11$ years ( $n=32, M=124.50$ months, $S D=4.23$ months). Gender was evenly distributed between schools and age groups. Only one school had children in the youngest age group ( $n=32$ ), whereas 14 older participants were from that school and 18 from the other.

\section{Procedure}

Children participated individually under the supervision of an experimenter. The younger children were invited to participate in the study and were interviewed individually at a table by an adult experimenter. The older children self-completed the questionnaire at a separate table. Children were assigned randomly to condition.

\section{Materials}

Participants were given a questionnaire and either completed this themselves or each question was read out and they pointed to their answer. The front page explained that, 'We are asking children about the Summer School. Most of the questions can be answered by putting a tick next to a picture of a face'. There followed a series of questions about the weather that day with an explanation of which face to tick to describe it. Each point on the 5-point scale was represented by a circular 'feeling face'. The scale had the mouth in a downward position (=1) through borizontal (=3), to a large smile position $(=5)$. This page was used to check that participants understood how to use the response scale.

The next page asked about specific evaluations of their summer school. 'Please tell us what you think about the summer school here at [School] by ticking the face that shows what you feel'. The questions asked if there was enough to do, if it was fun, whether the people were nice, whether it was a good place to be, whether it was good for sport and whether the activities were exciting. The next question tapped the global judgment of their summer school, by asking 'How much do you like your summer school scheme at [School]'. A parallel question was asked about the other school: 'How much do you think you would like to be at the summer school at [other School] instead?'. For these two questions tapping the global in-group and global out-group evaluation, the face scales were anchored with not at all (1) and very much (5).

The next page presented 'some of the things said by children who went to [Summer School] last year'. This page presented statements by three characters, Peter, Jo and finally Gill. Jo was always the deviant member. Peter and Gill were normative members and were conceptually intended to be interchangeable, differing only in terms of gender. Gender is not strictly relevant to the present hypotheses, or to the comparison between the summer schools, and we have no a priori reason to expect gender to affect responses. However, we were aware that previous research had revealed pronounced in-group gender bias among children (e.g. Bigler, 1995; Martin, 1989; Powlishta, 1995a, 1995b; Yee \& Brown, 1994). As a precaution, and to minimize the complexity of the design, we made the deviant's gender ambiguous, but we counterbalanced which normative member was evaluated, such that half the children judged a male normative target and the others judged a female normative target. If gender bias is present it will be revealed as a preference for the own-gender normative 
members over the opposite-gender normative members, regardless of which summer school the members are attending.

The referent school varied depending on whether participants were in the in-group or out-group member condition. One normative member said, 'I really like the [Summer School], there's lots of different things you can do, and the [Summer School] is a great place to be during the summer'. The second normative member said, 'The [Summer School] scheme is good for sports and games and the people are really nice at the [Summer School]'. The deviant member made a positive statement about both schools. These statements were actually kept constant across all conditions, and the name Jo was chosen because it is equally appropriate for either gender in the UK. Jo said 'All the things you can do at [own Summer School] are great fun, but I think the [other Summer School] would be good because there are lots of exciting things to do there'. We kept this statement constant across conditions so we could ensure that the deviant members were comparable. ${ }^{1}$

The rest of the questionnaire asked about two of the group members, beginning with a normative member (either Peter or Gill, depending on Version condition), and followed by the deviant member (Jo). For each of the members, participants were first reminded of what that member had said, and then were asked 10 questions. The first two questions constituted a perceptual accuracy check to see whether participants understood which preferences the member had expressed. 'What does [member] feel about being at the [Summer School]?', and 'what do you think [member] would feel about going to the [other Summer School] instead?'. A measure of member-group typicality was designed to check that the normative targets were viewed as more typical (i.e. normative) of their groups than were the deviant targets. These items asked, 'How many other children at [Summer School] would think the same as [member]?'. As in the Norm Check study described earlier, the options ran from 'Almost all', to 'A lot' to 'Quite a few', 'Hardly any' and 'None'. Above each label was a schematic picture that depicted $40,18,10,4$ or no people, respectively. Two questions used the face scales to measure perceived same-group inclusion and otber-group inclusion. These were included to see whether children understood the social implications of the targets' attitudes, in terms of their likely acceptability to members of each group. The questions were, 'How do you think other children at [Summer School] would feel towards [member]?', and 'How do you think children who go to the [other Summer School] would feel toward [member]?'.

Four items tapped member evaluations by asking, 'how do you feel towards [member]?', 'how do you feel about what [member] said?', 'how much would you like to be [member's] friend?', and 'in a game, how much would you want [member] to be on your team?'. Responses were made using the feeling face scales. After completing the member ratings for the normative and deviant member, participants were asked if they had any questions, and were then offered the choice of a cartoon sticker or a coloured pen for participating.

\footnotetext{
We used the independent statements because this allowed us to ensure that the deviant expressed an identical attitude in both the in-group and the out-group condition, and that we only manipulated deviance in terms of one target. Using the blatant (interdependent) statements would have meant the deviants expressed negativity to their own group at the same time as positivity to the out-group, which would have made interpretation of the results more difficult.
} 


\section{Results}

We first checked whether there were any main effects of school among the older age group. Across the dependent variables there was no significant multivariate effect of school, $F(12,20)=0.48 .^{2} \mathrm{~A}$ similar analysis involving participant gender was marginally significant, multivariate $F=1.89, p=.057$. These effects were in any case not directly relevant to the main hypotheses of the study, and interactions with gender and school did not significantly qualify any of the effects reported below. Because of the marginal multivariate main effect of gender, and as a precaution to reduce error variance, we included gender as a covariate for the remaining analyses.

\section{Specific in-group evaluations}

The six items used to tap these evaluations were strongly intercorrelated. Factor analysis revealed that four of the items shared a common factor, accounting for $40 \%$ of the total variance. We averaged the responses to these four items to create a composite measure of specific evaluation (Cronbach's $\alpha=.76$ ). All participants were highly positive, and the mean score (4.63) differed significantly from the scale midpoint of 3.0, $t(63)=27.0, p<.001$. Next, we included this measure along with the two remaining items (whether the people were nice and whether the school was good for sports) in a MANCOVA with Age and Group as independent variables and Sex as a covariate. The only significant multivariate effect was for $\operatorname{Sex}, F(3,53)=2.95, p=.041$. The univariate effect of Sex was significant only for the composite measure, $F(1,55)=4.73, p=.034$. Male participants were slightly less positive $(M=4.53)$ than female participants $(M=4.81)$. There were no significant main effects or interactions involving Age or Group.

\section{Global in-group and out-group evaluations}

These items were answered before participants received information about the target individuals. Evaluations of the two groups were analysed using an Age $\times$ Target Group (in-group vs. out-group) ANCOVA with repeated measures on the last factor and Sex as a covariate. As expected, the only significant effect was for Target Group, $F(1,60)=220.57$, $p<.001$ (all other $F \mathrm{~s}<1.80$ ). The in-group was rated more positively than the out-group ( $M=4.70, S D=0.63$, and $M=2.23, S D=1.19$, respectively), and both means differed significantly from the scale midpoint, $t_{\text {ingroup }}(63)=21.48, p<.001 ; t_{\text {outgroup }}(63)=5.14$, $p<.001$. Thus, as can be seen in Table 1 , regardless of age, participants showed significant global bias in favour of the in-group and against the out-group.

\section{Perceptual accuracy check}

The perceptual accuracy measure was designed to detect whether participants were aware that the deviant member was more positive than the normative member about attending the opposing summer school scheme. To check whether participant gender and gender of the normative target (Version: Peter vs. Gill) affected these judgments,

\footnotetext{
2 Because most of the younger children were within one of the schools this analysis was restricted to the older children. There were no significant multivariate or univariate effects of School. We also repeated all the remaining analyses using only the school with both age groups and found all the results remained significant. Therefore, we are confident that there are no statistical artifacts associated with school, and the remaining analyses collapsed across this factor.
} 
Table I. Means (SD) showing the effects of Group and Age on judgments of normative and deviant targets

\begin{tabular}{|c|c|c|c|c|c|c|c|}
\hline & \multicolumn{4}{|c|}{ In-group } & \multicolumn{3}{|c|}{ Out-group } \\
\hline & \multicolumn{2}{|c|}{$6-7$ years } & \multicolumn{2}{|c|}{$10-11$ years } & $6-7$ years & \multicolumn{2}{|c|}{ 10-11 years } \\
\hline & Normative & Deviant & Normative & Deviant & Normative Deviant & Normative & Deviant \\
\hline $\begin{array}{l}\text { Global evaluation } \\
\text { of in-group }\end{array}$ & 4.69 & $(1.01)$ & 4.56 & $(0.51)$ & $4.75(0.45)$ & 4.86 & $(0.36)$ \\
\hline $\begin{array}{l}\text { Global evaluation } \\
\text { of out-group }\end{array}$ & 2.25 & $(1.07)$ & 2.44 & $(1.15)$ & $2.31(1.45)$ & 1.86 & $(1.10)$ \\
\hline $\begin{array}{l}\text { Member's attitude } \\
\text { to same school }\end{array}$ & $4.94(0.25)$ & $4.00(0.97)$ & $4.94(0.24)$ & $3.56(0.98)$ & $4.81(0.40) 3.94$ & $5.00(0.00)$ & $3.14(1.29)$ \\
\hline $\begin{array}{l}\text { Member's attitude } \\
\text { to opposite school }\end{array}$ & $3.31(1.20)$ & $4.38(0.89)$ & $2.67(1.14)$ & $4.11(1.08)$ & 3.50 & $3.57(1.02)$ & $4.21(0.98)$ \\
\hline $\begin{array}{l}\text { Member's own- } \\
\text { group typicality }\end{array}$ & $4.31(0.48)$ & $2.69(1.25)$ & $4.17(0.99)$ & $2.00(1.19)$ & $2.87(1.03) 2.94$ & ) $2.57(1.02)$ & $2.00(1.18)$ \\
\hline $\begin{array}{l}\text { Group inclusion } \\
\text { of member }\end{array}$ & $1.13(1.46)$ & $-0.75(1.07)$ & )।.67 (1.24) & $-1.17(1.82$ & 2) $0.38(1.46) 0.50(1.27$ & ) $1.14(1.10)$ & $-0.07(1.90)$ \\
\hline $\begin{array}{l}\text { Evaluation of } \\
\text { member }\end{array}$ & $4.22(0.97)$ & $3.73(1.11)$ & $4.06(0.62)$ & $3.01(1.05)$ & $3.70(0.64) 3.75$ & $2.75(0.98)$ & $3.18(1.18)$ \\
\hline
\end{tabular}

Note. For the global evaluation measures the judgments were made about the group as a whole, and therefore there are no separate means relating to normative and deviant members.

we first conducted a Sex $\times$ Version $\times$ Age $\times$ Group $\times$ Destination (same vs. other school) ANOVA on judgments of how the normative member would feel about going to their own summer school, and to the other summer school. Sex, Version, Age and Group were between-participants variables and Destination was a within-participants variable. There were no significant main effects or interactions involving Sex, Version or Destination (all $F \mathrm{~s}(1,49)<2.30$, all $p s>.15)$ and we therefore collapsed across these factors, including Sex as a covariate in later analyses.

An Age $\times$ Group $\times$ Member ANCOVA examined perceptions of normative vs. deviant member's statements about attending their summer school (see Table 1). Participants perceived that the normative member was more positive $(M=4.92$, $S D=0.27)$ than the deviant member $(M=3.67, S D=1.17), F(1,60)=79.46, p<.001$. This effect was qualified by an Age $\times$ Member interaction, $F(1,60)=6.38, p=.014$. Although highly significant within both age groups, perceptions of members differed less within the younger age group $\left(M_{\text {normative }}=4.88, S D=0.34 ; M_{\text {ceviant }}=3.97\right.$, $S D=1.15 ; F(1,62)=20.77, p<.001)$ than the older age group $\left(M_{\text {normative }}=4.97\right.$, $\left.S D=0.18 ; M_{\text {deviant }}=3.38, S D=1.13 ; F(1,62)=64.25, p<.001\right)$.

A similar ANCOVA on perceptions of members' statements about attending the alternative summer school revealed that the normative member was expected to feel less positive than the deviant member $\left(M_{\text {normative }}=3.23, S D=1.22, M_{\text {deviant }}=4.19\right.$, $S D=0.94 ; F(1,60)=37.92, p<.001)$. This effect was qualified by a significant Group $\times$ Member interaction, $F(1,60)=4.66, p=.035$. The simple effect of member was larger within the in-group condition $\left(M_{\text {normative }}=2.97, S D=1.19, M_{\text {deviant }}=4.24\right.$, $S D=0.99 ; F(1,62)=38.39, p<.001)$ than in the out-group condition ( $M_{\text {normt }}$ tive $\left.=3.53, S D=1.20, M_{\text {deviant }}=4.13, S D=0.9 ; F(1,62)=7.62, p=.008\right)$. Thus, participants in both age groups accurately detected that the deviant target was more favourable to the alternative summer school than were normative targets. 


\section{Member typicality}

We coded the typicality measure from 1 (none) to 5 (almost all). The ANCOVA on the member typicality item revealed significant main effects of Age and Member. Consistent with the manipulation, the normative member was viewed as significantly more typical $(M=3.00, S D=0.93)$ than the deviant member $(M=2.41, S D=1.20), F(1,60)=10.81$, $p=.002$. Therefore, children were able to understand that the deviant was less typical than normative targets. In addition, younger children viewed both members as more typical $(M=2.95, S D=0.77)$ than did the older children $(M=2.44, S D=0.77)$, $F(1,59)=6.77, p=.012$.

\section{Group inclusion}

The measures of group inclusion were intended to capture children's interpretation of the meaning of deviance for dynamics within the target's group. For each target, we subtracted the rating of inclusion in the alternative group from the rating of inclusion in that member's own group (raw means are shown in Table 1). This provided a measure of relative group inclusion. On this index a positive score reflects that the member is perceived to be more welcomed for inclusion by his or her own group than by the alternative group. A negative score reflects the reverse.

An ANCOVA on the group inclusion score for the normative and deviant members revealed a significant main effect of Member, $F(1,60)=28.75, p<.001$, a significant Age $\times$ Member interaction, $F(1,60)=4.52, p=.038$, and a significant Group $\times$ Member interaction $F(1,60)=11.20, p=.001$. Consistent with the hypothesis that older children would be more sensitive to the implications of deviance, simple effects analysis revealed that the effect of Member was larger in the older age group, $F(1$, $62)=27.07, p<.001$ than the younger age group, $F(1,62)=4.59, p=.036$. Older children judged the relative own-group inclusion of normative members $(M=1.44$, $S D=1.19)$ and opposite group-inclusion of the deviant members $(M=-0.69$, $S D=1.91)$ to be larger than did younger children $\left(M_{\text {normative }}=0.75, S D=1.48\right.$, and $M_{\text {deviant }}=-0.13, S D=1.31$ ).

Simple effects analyses showed that the effect of member was significant within the ingroup condition, $F(1,62)=39.94, p<.001$, but not within the out-group condition, $F(1$, $62)=1.55$. The normative member was seen as being included in their own group in both the in-group and out-group conditions $\left(\mathrm{M}_{\text {ingroup }}=1.41, S D=1.35, \mathrm{M}_{\text {out-group }}=0.73\right.$, $S D=1.34), F(1,59)=3.76, p=.057$, whereas the deviant member was seen as attracting other-group inclusion in the in-group condition $(M=-0.97, S D=1.51)$ and a weak own-group inclusion in the out-group condition $(M=0.23, S D=1.59), F(1,59)$ $=8.92, p=.004$.

\section{Member evaluations}

The four items tapping evaluations of each member were first factor analysed with varimax rotation. This revealed two distinct factors, one consisting of normative member evaluations (19\% of total variance) and the other of deviant member evaluations (52\% of the total variance). For each member, we collapsed the sets of items to form a composite measure, and both were internally reliable (Cronbach's $\alpha$ for the normative member $=.83, \alpha$ for the deviant member $=.87$ ). The Age $\times$ Group $\times$ Member ANCOVA on this measure revealed significant main effects of Age, $F(1,59)=$ $7.29, p=.009$, Group, $F(1,59)=4.04, p=.049$ and Member, $F(1,60)=5.33, p=.024$. 
Older children were less positive $(M=3.29, S D=0.88)$ than younger children $(M=$ 3.85, $S D=0.84)$. Evaluations of the in-group members were more positive $(M=3.74$, $S D=0.82)$ than evaluations of the out-group members $(M=3.37, S D=0.95)$. Evaluations of the normative member were more positive $(M=3.72, S D=0.96)$ than evaluations of the deviant member $(M=3.41, S D=1.11)$. These were qualified by a significant Group $\times$ Member interaction, $F(1,59)=19.35, p<.001$, and a significant Age $\times$ Group $\times$ Member interaction, $F(1,59)=4.26, p=.043$.

To understand the three-way interaction we examined the simple main effects and the simple Group $\times$ Member interactions within each age group. ${ }^{3}$ Within the younger age group the effect of Group was significant, $F(2,59)=47.67, p<.001)$, but not the main effect of Member, $F(1,62)=1.38, p=.24$, and the Group $\times$ Member interaction was also non-significant, $F(2,60)=2.31, p=.11$. In the older age group, the effect of Group was significant, $F(2,59)=47.67, p<.001$, and so was the main effect of Member $F(1,62)=4.59, p=.036$. Moreover, the Group $\times$ Member interaction was highly significant, $F(2,60)=13.45, p<.001$. We then examined the simple effects of Member within levels of Group for the older age group. This revealed a significant effect of Member in the in-group condition, $F(1,62)=22.81, p<.001$, and marginal effect in the out-group condition, $F(1,62)=3.00, p=.09$. As shown in Table 1 and Fig. 1 , both younger and older children preferred a normative in-group member over a deviant in-group member. However, only the older children were less favourable towards an out-group normative member than an out-group deviant.

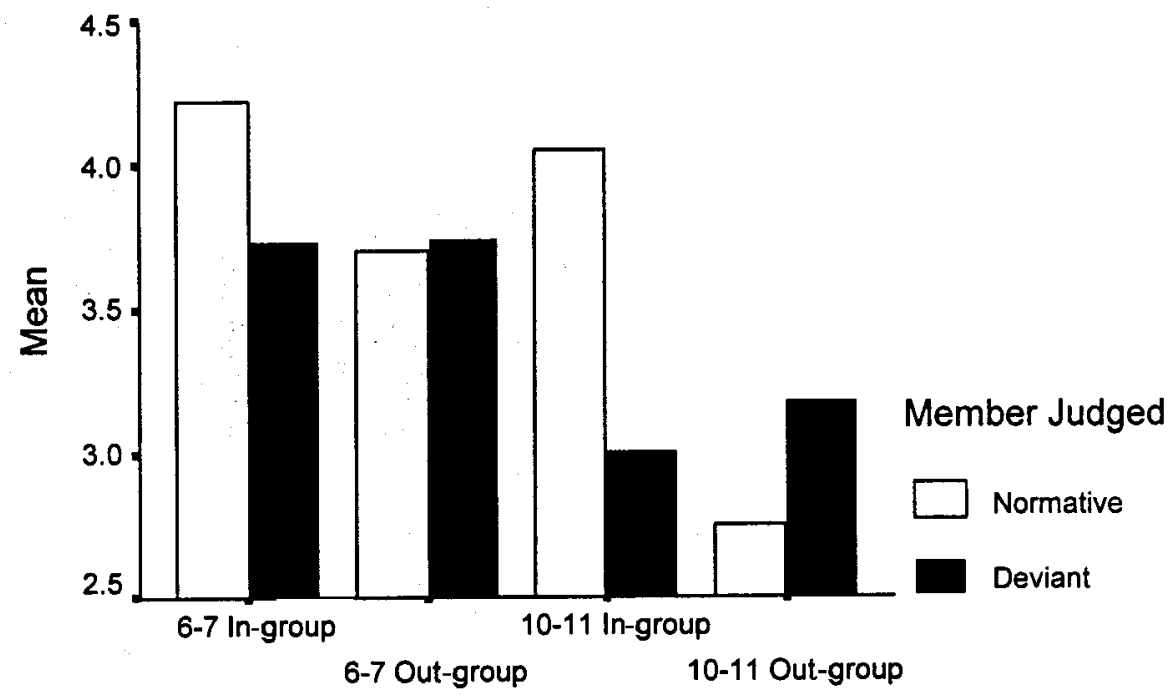

Age and Group

Figure I. Effects of Age and Group membership on member evaluations.

\footnotetext{
${ }^{3}$ Decomposing the Group $\times$ Member interaction, in the in-group condition there was a significant simple effect of Member $\left(M_{\text {nomative }}=4.13, S D=0.79, M_{\text {deviant }}=3.35, S D=. I 2\right), F(I, 62)=24.16, p<.00 I$. This effect was not significant in the out-group condition $\left(M\right.$ namative $\left.=3.26, S D=0.94, M_{\text {deviant }}=3.48, S D=I . I 2\right), F(I, 62)=1.78$. The simple effect of Condition was significant for normative members $F(I, 62)=20.19, p<.00 I$, but not deviant members, $F(I, 62)=0 . I I$.
} 


\section{Additional analyses}

We believe that the process underlying subjective group dynamics is that group members engage in intragroup differentiation as a means of sustaining in-group positivity. We further hypothesized that this process emerges developmentally later than simple in-group bias. It follows that there should be stronger relationships between in-group bias and intragroup differentiation among older children than younger children. To examine these ideas and to maximize power, we constructed three measures to capture intergroup and intragroup differentiation across in-group and out-group conditions. The first measure, in-group bias, was the global evaluation of the in-group minus the global evaluation of the out-group. A higher score represents stronger in-group bias. This represents a form of intergroup differentiation. The second measure, which taps differential inclusiveness between the normative and deviant member subtracts the relative group inclusiveness of the deviant member from the relative group inclusiveness of the normative member. Thus, a higher figure represents stronger differentiation between these members. The third measure, differential evaluation, was constructed by subtracting the evaluation of the member who should be relatively unattractive to the in-group (i.e. the deviant in-group member or the normative out-group member) from the evaluation of the member who should be relatively attractive to the in-group (i.e. the normative in-group member or the deviant out-group member, respectively). Higher scores represent a stronger preference for the member who relatively provides most support for the in-group. Differential inclusiveness and differential evaluation represent forms of intragroup differentiation. If our analysis is correct, the relationship between intergroup and intragroup differentiation should strengthen with age. Moreover, the relationship between differential inclusiveness and differential evaluation should be stronger among older children.

In the younger age group $(N=32)$ in-group bias was not significantly related to differential inclusiveness or to differential evaluation $(r s<.26)$. Differential inclusiveness was significantly related to differential evaluation, $r=.37, p=.04$. Among the older children $(N=32)$ in-group bias was correlated significantly with differential inclusiveness, $r=.46, p=.008$, and positively, but not significantly to differential evaluation $(r=.20)$. However, differential inclusiveness was in turn significantly related to differential evaluations, $r=.59, p<.001$. Thus, in the older age group the more that children favoured the in-group over the out-group as a whole, the more they distinguished the group inclusiveness of normative and deviant members, and the more they made this distinction, the more that they favoured in-group and out-group members who were relatively in-group supportive. In contrast, among the younger children there was no evidence of any relationship between intergroup and intragroup differentiation processes.

In order to examine directly how age moderated the relationships among intergroup and intragroup judgments, we regressed in-group bias and age, and then the age $\times$ bias interaction term, on to differential inclusiveness. The effect of bias was significant, $B=0.38, \beta=0.27, t=2.21, p=.03$, the effect of age was marginally significant $B=0.02, \beta=0.21, t=1.76, p=.08$, and the interaction was significant $B=0.02$, $\left.\beta=1.46, t=2.34, p=.02, R^{2}=.18, F(3,60)=4.72, p=.005\right)$ In-group bias is more strongly associated with differential inclusiveness among the older children.

We then examined the effects of bias and age on differential evaluations. The effect of age was significant, $B=.01, \beta=.28, t=2.35, p=.02$, the effect of bias was marginally significant $B=.16, \beta=.22, t=1.87, p=.06 ; R^{2}=.12, F(2,60)=4.56, p=$ .014 , but the interaction was non-significant. Next we examined the effect of 


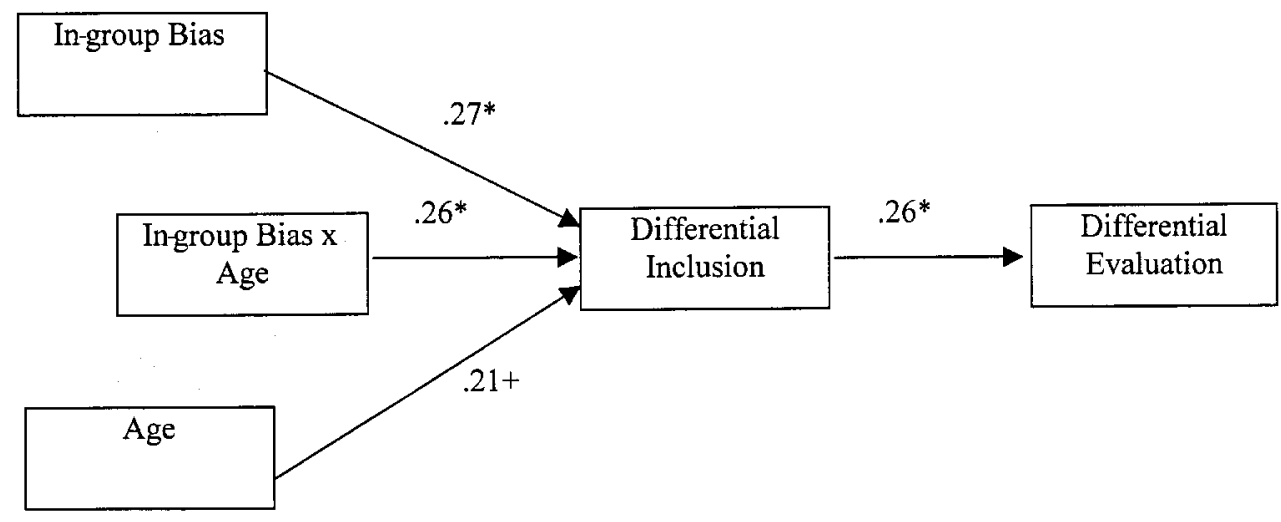

Figure 2. Path diagram of the effects of intergroup bias and age on differential inclusion and differential evaluation. Path weights are standardized group coefficients; ${ }^{*} p<.5 ;+p=.8$.

differential inclusiveness on differential evaluations. This was highly significant $\beta=.26$, $\beta=.52, t=4.81, p<.0001$. We used path analysis to examine the effect of age, intergroup bias, their interaction and differential inclusiveness on differential evaluations. Only the effect of differential inclusiveness was significant, $B=.25$, $\beta=.50, t=4.20, p<.001 ; R^{2}=.32, F(4,59)=7.03, p<.001$. These results are summarized in the path model shown in Fig. 2, which shows that age, bias and their interaction affected differential inclusiveness, which in turn affected differential evaluations. Moreover, the effects of age and in-group bias on differential evaluations were mediated significantly by differential inclusiveness, $Z=2.28, p=.02 .{ }^{4}$ The direct paths from age and bias to differential evaluations were non-significant $(\beta s=0.17$ and $0.10, t s=1.52,0.90$, respectively).

These analyses show that the relationship between in-group bias and differential inclusiveness increases with age. Moreover, in-group bias is not directly associated with evaluative differentiation among group members. Rather, the relationship between ingroup bias and evaluative differentiation is mediated by differential inclusiveness. This evidence is consistent with the idea that the subjective integration of intergroup and intragroup differentiation emerges later than simple intergroup differentiation.

\section{Discussion}

A number of results emerge clearly from this study. First, the summer schools manifestly constituted a valued group membership for the children. As well as being very positive about their summer school, they all showed significant bias in favour of their own vs. the alternative summer school on the global bias measures. This was not affected by which summer school they attended, their gender or their age. This finding is consistent with social identity theory and previous research showing that young children readily show in-group bias in minimal or transitory groups and that such bias continues into middle-childhood (Bigler, 1995; Bigler et al., 1997, 2001; Durkin \&

\footnotetext{
${ }^{4}$ To test the significance of mediation by differential inclusiveness of the total variance in differential evaluations explained by both bias and age and their interaction, we used the Goodman (I) version of the Sobel test (Goodman, 1960; see also Baron \& Kenny, 1986, and MacKinnon, Warsi, \& Dwyer, 1995). Analysis of the unique mediation of bias and age also revealed significant mediation of in-group bias, $Z=1.97, p=.049$.
} 
Judge, 2001; Nesdale \& Flesser, 2001; Spielman, 2000; Vaughan et al., 1981). A reduction of in-group bias might have been expected given cognitive-developmental theory's prediction that the development of individuated perception with age should result in less intergroup discrimination. However, we found no support either for the idea that older children might judge targets equally favourably (because all expressed positive sentiments) or that they might generally favour even-handed (deviant) targets over partisan (normative) targets on the basis of some moral principle (cf. Damon, 1977; Hoffman, 2000).

Also, our preliminary study to check intergroup norms showed that children in both age groups were clearly aware of intergroup norms that prohibit enthusiasm about outgroup schools. This is consistent with the idea that loyalty norms are fairly basic and pervasive in society, perhaps for evolutionary as well as social reasons (Kurzban \& Leary, 2000; Zdaniuk \& Levine, 2001). Moreover, in the main study we found that children in both age groups were also able to detect that normative and deviant group members had different attitudes about attending each summer school. These perceptions were somewhat more extreme among older children. Both age groups were also clearly aware that the deviant target was less typical than the normative target. Interestingly, children were also more sensitive to the differences between normative and deviant members when judging in-group members rather than out-group members. These results add to the limited developmental evidence that converges with the adult literature on the out-group homogeneity effect, showing that intragroup differentiation is often more pronounced for in-groups than for out-groups (cf. Brauer, 2001; Powlishta 1995a; Simon, 1992; Simon \& Brown, 1987).

In line with SGD's predictions, children in both age groups were aware that deviant members were atypical, but older children were more attuned to the social implications of this atypicality. When asked to rate how acceptable the target would be from the perspective of other members of the group (relative group inclusion), differentiation between these members was significantly greater among older children. This result reveals that younger children's awareness of differences among group members does not automatically enable them to understand the implications of these differences for relationships within and between groups. It is also compatible with research which suggests that below 8 years of age children do not fully understand self-presentation, or appreciate the perspective of the individual in relation to the social group (see Banerjee \& Lintern, 2000; Banerjee \& Yuill, 1999a, 1999b; Bennett \& Yeeles, 1990).

The subjective group dynamics approach holds that evaluative differentiation among group members serves to sustain valued in-group distinctiveness. Therefore, in an intergroup context in which deviants imply support for opposing group norms, normative in-group members should be preferred over deviant in-group members, and deviant out-group members should be preferred over normative out-group members. The results on the member evaluations showed that only the older children displayed this pattern.

The path analysis adds weight to the conclusion that subjective group dynamics begin to operate later than simple intergroup differentiation. The relationship between in-group bias and differential inclusiveness between the normative and deviant members increased significantly with age, and the combined effects of age and ingroup bias on differential evaluation were fully mediated by differential inclusion. These data are clearly consistent with the idea that the linkage between intergroup and intragroup differentiation increases with age.

The findings of this study suggest that with increasing age children do not reduce or 
abandon category-based judgments, instead they develop the ability to integrate both intergroup and intragroup differentiation. The development of multiple classification and social comparison skills with age means that children can perceive within-group differences by attending to 'individuating' information. However, older children are still able, and often willing, to maintain their social identification with particular salient categories or groups by giving evaluative approval for in-group and out-group individuals who offer relative support for the in-group norms (i.e. out-group deviants and in-group normative targets).

The notion that children judge group members by engaging in both intergroup and intragroup differentiation is compatible with self-categorization theory's claim that individual and categorical perceptions are not opposed processes, since social perception is inherently categorical (Rutland, 1999; Simon, 1997; Spears \& Haslam, 1997). Individuating information (e.g. displaying the attribute of loyalty) can either act as a cue for a related set of individual traits or be related to behaviour of a particular category of people, depending on the social context (Abrams, 1996; Abrams \& Hogg, 2001; Oakes, Haslam, \& Turner, 1994). When a social context is well defined in terms of a pre-existing, salient intergroup differentiation, generic behavioural or trait qualities can also provide a prescriptive norm. For example, in a military context, loyalty is a generic prescriptive ideal that can be used to define the in-group as superior to outgroups. Even though loyalty should characterize military personnel of all types and nationalities, each army would want to show that they have more of it, proving they are 'better'. Consistent with this idea, Abrams et al. (2002) and Marques et al. (2001) found that group members evaluated in-group members more highly relative to out-group members when they behaved consistently with generic norms. The present research shows that, even for a transient but meaningful group membership, sensitivity to the intergroup implications of loyalty emerges clearly by the age of 11 years.

\section{Conclusions}

The present study indicates that as children get older they begin to comprehend multiple categories and they also show evidence of both intragroup and intergroup differentiation. That is, children do not merely add individuated judgment to categorybased judgment, but they integrate the two in a meaningful way. Nesdale (1999) found evidence that with age children show better memory for in-group stereotypeinconsistent traits and attribute negative stereotype-inconsistent behaviour to stable internal characteristics. This is compatible with our finding that older children were more sensitive to intragroup differences. The present study also augments Nesdale's (1999) findings by examining judgments of deviant members in the context of direct intergroup, as well as intragroup comparisons.

The present findings support the idea that subjective group dynamics emerge in children later than basic in-group preferences. Both age groups showed evidence of significant in-group bias, whereas only the older children showed evaluative bias in both intergroup and intragroup judgments. We are conscious that this pattern of findings may be restricted to relatively novel intergroup settings. It is conceivable that in the case of strongly socially prescribed norms (e.g. gender- or age-related behavioural norms), younger children might be more adept at recognizing deviance and its implications. However, in the case of relatively novel groups, it seems likely that younger children would find it less easy to understand generic principles, such as those 
of group loyalty, that provide a basis for implicit prescriptive norms. For methodological reasons, we operationalized deviance in a relatively innocuous and subtle way (expression of positive attitude towards an out-group). It is possible that younger children may be better able to interpret deviance when it involves actions that more directly challenge the member's own group (see Mummendey \& Otten, 1998). Further research is required to investigate these issues. Not withstanding these caveats, our results are consistent with the idea that there is a developmental strengthening of the relationship between in-group bias and intragroup differentiation that evaluatively supports in-group enhancing group members. Taken together, these results underline the potential value of a developmental model for understanding the emergence of subjective group dynamics.

\section{References}

Aboud, F. E. (1988). Children and prejudice. Oxford: Blackwell.

Aboud, F. E., \& Amato, M. (2001). Developmental and socialisation influences on intergroup bias. In R. Brown \& S. L. Gaertner (Eds.), Blackwell handbook of social psychology: Intergroup processes (pp. 65-85). Oxford: Blackwell.

Abrams, D. (1985). Focus of attention in minimal intergroup discrimination. British Journal of Social Psychology, 24, 65-74.

Abrams, D. (1989). Differential association: Social developments in gender identification during adolescence. In S. Skevington \& D. Baker (Eds.), The social identity of women (pp. 59-83). London, Sage.

Abrams, D. (1996). Social identity, self as structure and self as process. In W. P. Robinson (Ed.), Social groups and identities: Developing the legacy of Henri Tajfel (pp. 143-168). London: Butterworth Heinemann.

Abrams, D., \& Brown, R. J. (1989). Selfconsciousness and social identity: Selfregulation as a group member. Social Psychology Quarterly, 52, 311-318.

Abrams, D., \& Hogg, M. A. (2001). Collective self. In M. A. Hogg \& S. Tindale (Eds.), Blackwell handbook of social psychology, Vol. 3: Group processes (pp. 425-461). Oxford: Blackwell.

Abrams, D., Marques, J. M., Bown, N., \& Dougill, M. (2002) Anti-norm and pro-norm deviance in the bank and on the campus: Two experiments on subjective group dynamics. Group Processes and Intergroup Relations, 5, 163-182.

Abrams, D., Marques, J. M., Bown, N. J., \& Henson, M. (2000). Pro-norm and anti-norm deviance within in-groups and out-groups. Journal of Personality and Social Psychology, 78, 906-912.

Abrams, D., Marques, J. M., Randsley de Moura, G., Hutchison, P., \& Bown, N.J. (in press). The maintenance of entitativity: A subjective group dynamics approach. In V. Y. Yzerbyt, C. M. Judd, \& O. Corneille (Eds.), The psychology of group perception: Contribution to the study of bomogeneity, entitativity, and essentialism. Philadelphia, PA: Psychology Press.

Augoustinos, M., \& Rosewarne, D. L. (2001). Stereotype knowledge and prejudice in children. British Journal of Developmental Psychology, 19, 143-156.

Banerjee, R. \& Lintern, V. (2000). Boys will be boys: The effect of social evaluation concerns on gender typing. Social Development, 9, 397-408.

Banerjee, R. \& Yuill, N. (1999a). Children's explanations of self-presentational behaviour. European Journal of Social Psychology, 29, 105-111.

Banerjee, R. \& Yuill, N. (1999b). Children's understanding of self-presentational display rules: Associations with mental-state understanding. British Journal of Developmental Psychology, 17, 111-124.

Baron, R. M., \& Kenny, D. A. (1986). The moderator-mediator variable distinction in social psychological research: Conceptual, strategic, and statistical considerations. Journal of Personality and Social Psychology, 51, 1173-1182. 
Barrett, M., \& Short, J. (1992). Images of European people in a group at 5-10 year-old English schoolchildren. British Journal of Development Psychology, 34, 902-909.

Bennett, M., Lyons, E., Sani, F., \& Barrett, M. (1998). Children's subjective identification with the group and in-group favouritism. Developmental Psychology, 34, 902-909.

Bennett, M., \& Yeeles, C. (1990). Children's understanding of the self-presentational strategies of ingratiation and self-promotion. European Journal of Social Psychology, 20, 455-461.

Bigler, R. S. (1995). The role of classification skill in moderating environmental influences on children's gender stereotyping: A study of the functional use of gender in the classroom. Child Development, 66, 1072-1087.

Bigler, R. S., Brown, C. S., \& Markell, M. (2001). When groups are not created equal: Effects of group status on the formation of intergroup attitudes in children. Child Development, 72 , 1151-1162.

Bigler, R. S., Jones, L. C., \& Lobliner, D. B. (1997). Social categorisation and the formation of intergroup attitudes in children. Child Development, 68, 530-543.

Bigler, R. S., \& Liben, L. S. (1992). Cognitive mechanisms in children's gender stereotyping: Theoretical and educational implications of a cognitive-based intervention. Child Development, 63, 1351-1363.

Black-Gutman, D., \& Hickson, F. (1996). The relationship between racial attitudes and socialcognitive development in children: An Australian study. Developmental Psychology, 32, 448456.

Brauer, M. (2001). Intergroup perception in the social context: The effects of social status and group membership on perceived out-group homogeneity and ethnocentrism. Journal of Experimental Social Psychology, 37, 15-31.

Brewer, M. B., \& Brown, R. (1998) Intergroup relations. In D. T. Gilbert, S. T. Fiske, \& G. Lindzey (Eds.), The handbook of social psychology (Vol. 2, pp. 554-594). New York: McGraw-Hill.

Cameira, M., Marques, J. M., Abrams, D., \& Serôdio, R. G. (2001). Social attraction and leadership as a function of intragroup and intergroup contexts: A subjective group dynamics approach. Paper presented at the British Psychological Society Annual Conference, Belfast.

Cameron, J. A., Alvarez, J. M., Ruble, D., \& Fuligni, A. J. (2001). Children's lay theories about ingroups and out-groups: Reconceptualizing research on prejudice. Personality and Social Psychology Review, 5, 118-128.

Crick, N.R. (1997). Engagement in gender normative versus non-normative forms of aggression. Links to social psychological adjustment. Development Psychology, 33, 610-612.

Damon, W. (1977). The social world of the child. San Francisco: Jossey-Bass.

Doyle, A., \& Aboud, F. (1995). A longitudinal study of white children's racial prejudice as a socialcognitive development. Merrill-Palmer Quarterly, 41, (2), 209-228.

Durkin, K., \& Judge, J. (2001). Effects of language and social behaviour on children's reactions to foreign people in television. British Journal of Developmental Psychology, 19, 597-612.

Emler, N.P., \& Reicher, S.D. (1995) Adolescence and delinquency. Oxford: Blackwell.

Goodman, L. A. (1960). On the exact variance of products. Journal of the American Statistical Association, 55, 708-713.

Hewstone, M., Rubin, M., \& Willis, H. (2002). Intergroup bias. Annual Review of Psychology, 53, 575-604.

Hoffman, M. L. (2000) Empathy and moral development: Implications for caring and justice. Cambridge: Cambridge University Press.

Hoover, J. H., Oliver, R., \& Hazler, R. J. (1992) Bullying: Perceptions of adolescent victims in the Midwestern USA. School Psychology Internaitonal, 13, 5-16.

Katz, P. A. (1976). The acquisition of racial attitudes in children. In P. A. Katz (Ed.), Towards the elimination of racism (pp. 125-154). New York: Pergamon.

Katz, P. A., Sohn, M., \& Zalk, S. R. (1975). Perceptual concomitants of racial attitudes in urban grade-school children. Developmental Psychology, 11, 135-144.

Kurzban, R., \& Leary, M. R. (2001) Evolutionary origins of stigmatization: The functions of social exclusion. Psychological Bulletin, 127, 187-208. 
Lambert, W. E., \& Klineberg, O. (1967). Children's views of foreign peoples: A cross-national study. New York: Appleton-Century-Crofts.

Levine, J. M. (1989) Reaction to opinion deviance in small groups. In P. B. Paulus (Ed.), Psychology of group influence (2nd ed., pp. 187-231). Hillsdale, NJ: Erlbaum.

MacKinnon, D. P., Warsi, G., \& Dwyer, J. H. (1995). A simulation study of mediated effect measures. Multivariate Behavioral Research, 30, 41-62.

Marques, J. M., Abrams, D., Paez, D., \& Martinez-Taboada, C. M. (1998). The role of categorisation and in-group norms in judgements of groups and their members. Journal of Personality and Social Psychology, 75, 976-988.

Marques, J. M., Abrams, D., \& Serôdio, R. G. (2001). Being better by being right: Subjective group dynamics and derogation of in-group deviants when generic norms are undermined. Journal of Personality and Social Psychology, 82, 436-447.

Marques, J. M., Paez, D., \& Abrams, D. (1998). Social identity and intragroup differentiation as subjective social control. In S. Worchel, J. F. Morales, D. Paez, \& J.-C. Deschamps (Eds.), Social identity: International perspectives (pp. 124-141). New York: Sage.

Martin, C. L. (1989). Children's use of gender-related information in making social judgements. Developmental Psychology, 25, 80-88.

Mummendey, A., \& Otten, S. (1998). Positive-negative asymmetry in social discrimination. In W. Streobe \& M. Hewstone (Eds.), European Review of Social Psychology, 9 (pp. 107-143). Chichester, UK: Wiley.

Nesdale, D. (1999). Developmental changes in children's ethnic preferences and social cognitions. Journal of Applied Developmental Psychology, 20, 501-519.

Nesdale, D. (2001). Development of prejudice in children. In M. Augoustinos \& K. J. Reynolds (Eds.), Understanding prejudice, racism and social conflict. London: Sage.

Nesdale, D., \& Flesser, D. (2001). Social identity and the development of children's group attitudes. Child Development, 72, 506-517.

Oakes, P., Haslam, S. A., \& Turner, J. (1994). Stereotyping and social reality. Oxford: Blackwell.

Piaget, J., \& Weil, A. (1951).The development in children of the idea of the homeland and of relations with other countries. International Social Science Bulletin, 3, 561-578.

Powlishta, K. K. (1995a). Intergroup processes in childhood: Social categorisation and sex role development. Developmental Psychology, 31, 781-788.

Powlishta, K. K. (1995b). Gender bias in children's perceptions of personality traits. Sex Roles, 32, 17-28.

Powlishta, K., Serbin, L. A., Doyle, A., \& White, D. R. (1994). Gender, ethnic, and body type biases: The generality of prejudice in childhood. Developmental Psychology, 30, 526-536.

Ruble, D. N., \& Dweck, C. S. (1995). Self-conceptions, person conceptions, and their development. In N. Eisenberg (Ed.), Review of personality and social psychology: Social development (Vol. 15, pp. 109-139). Thousand Oaks, CA: Sage.

Ruble, D. N., \& Frey, K. S. (1991). Changing patterns of comparative behavior as skills are acquired: A functional model of self-evaluation. In J. Suls \& T. A. Wills (Eds.), Social comparison: Contemporary theory and research (pp. 79-113). Hillsdale, NJ: Erlbaum.

Rutland, A. (1999). The development of national prejudice, in-group favouritism and self stereotypes in British children. British Journal of Social Psychology, 38, 55-70.

Sani, F., \& Bennett, M. (2001). Contextual variability in young children's gender in-group stereotype. Social Development, 10, 221-229.

Sani, F., Bennett, M., Agostini, L., Malucchi, L., \& Ferguson, N. (2000). Children's conceptions of characteristics figures of category members. Journal of Social Psychology, 140, 227-239.

Schuster, B. (1996) Rejection, exclusion, and harassment at work and in schools: An integration of results from research on mobbing, bullying and peer rejection. European Psychologist, 1, 293-317.

Sherif, M. (1966). Group conflict and co-operation: Their social psychology. London: Routledge \& Kegan Paul. 
Sherif, M., Harvey, O. J., White, B. J., Hood, W. R., \& Sherif, C. W. (1961). Intergroup conflict and cooperation: The robber's cave experiment. Norman: University of Oklahoma Press.

Simon, B. (1992). The perception of in-group and out-group homogeneity: Reintroducing the intergroup context. In W. Stroebe \& M. Hewstone (Eds.), European Review of Social Psychology (Vol. 3, pp. 1-30). Chichester, UK: Wiley.

Simon, B. (1997). Self and group in modern society: Ten theses on the individual self and the collective self. In R. Spears, P. Oakes, N. Ellemers, \& S. A. Haslam (Eds.), The social psychology of stereotyping and group life (pp. 318-335). Oxford: Blackwell.

Simon, B., \& Brown, R. J. (1987). Perceived intragroup homogeneity in minority-majority contexts. Journal of Personality and Social Psychology, 53, 703-711.

Spears, R., \& Haslam, S. A. (1997). Stereotyping and the burden of cognitive load. In R. Spears, P. Oakes, N. Ellemers, \& S. A. Haslam (Eds.), The social psychology of stereotyping and group life (pp. 171-207). Oxford: Blackwell.

Spielman, D. A. (2000). Young children, minimal groups, and dichotomous categorisation. Personality and Social Psychology Bulletin, 26, 1433-1441.

Tajfel, H. (1981). Human groups and social categories: Studies in social psychology. Cambridge: Cambridge University Press.

Tajfel, H., \& Turner, J. C. (1986). The social identity theory of intergroup behaviour. In S. Worchel $\&$ W. G. Austin (Eds.), The psychology of intergroup relations (pp. 7-24). Chicago: NelsonHall.

Turner, J. C., Hogg, M. A., Oakes, P. J., Reicher, S. D., \& Wetherell, M. S. (1987). Rediscovering the social group: A self-categorisation theory. Oxford: Blackwell.

Twenge, J. M., \& Baumeister, R. F. (in press). Social exclusion increases aggression and selfdefeating behaviour while reducing intelligent thought and prosocial behaviour. In D. Abrams, J. M. Marques, \& M. A. Hogg (Eds.), The social psychology of inclusion and exclusion. Philadelphia: Psychology Press.

Vaughan, G., Tajfel, H., \& Williams, J. A. (1981). Bias in reward allocation in an intergroup and an interpersonal context. Social Psychology Quarterly, 44, 37-42.

Verkuyten, M., Masson, K., \& Elffers, H. (1995). Racial categorisation and preference among older children in The Netherlands. European Journal of Social Psychology, 25, 637-656.

Williams, K. D. (2001) Ostracism: The power of silence. New York: Guilford Press.

Yee, M., \& Brown, R. J. (1994). The development of gender differentiation in young children. British Journal of Social Psychology, 33, 183-196.

Zdaniuk, B., \& Levine, J. M. (2001). Group loyalty: Impact of members' identification and contributions. Journal of Experimental Social Psychology, 37, 502-509.

Received I 7 July 2002; revised version received I3 September 2002 